ISSN: $1130-3743$

\title{
DRAMATIZACIÓN Y EDUCACIÓN: ASPECTOS TEÓRICOS
}

\author{
Drama and Education: Theoretical Framework
}

\section{Dramatisation et éducation: des aspects théoriques}

Luis NúñEz CuBERo y María del Rosario NavarRo SOLANO

Universidad de Sevilla. Facultad de Ciencias de la Educación. Departamento

de Teoría e Historia de la Educación y Pedagogía Social. C/. Camilo José Cela, s/n. 41018 Sevilla. Correo-e: Inc@us.es; rosanavarro@us.es

Fecha de recepción: enero de 2007

Fecha de aceptación definitiva: abril de 2007

BIBLID [(1130-3743) 19, 2007, 225-252]

RESUMEN

La dramatización constituye un espacio y herramienta educativa que permite desarrollar el currículum escolar en otras áreas, como la Educación Artística, la Expresión Corporal o la Lengua y la Literatura. Además, se muestra como un potente instrumento para el desarrollo de habilidades sociales y educación en valores, por su fuerte carácter interpersonal y relacional. En este trabajo pretendemos, en primer lugar, tratar de aclarar y diferenciar la amplia y confusamente utilizada terminología en torno al uso de la dramatización en la educación. En un segundo momento, describiremos el conjunto de aportaciones de la dramatización al currículum escolar, en particular en la etapa de Educación Primaria, en la cual los autores han desarrollado la mayor parte de sus investigaciones. Finalmente, abordaremos el interrogante, permanentemente presente, del lugar que ha de ocupar la dramatización en el currículum escolar.

Con este artículo queremos contribuir al avance de la construcción de un cuerpo teórico sobre la dramatización en la educación.

Palabras clave: dramatización, modelo integrado, educación en valores, habilidades sociales, trabajo en grupo. 
SUMMARY

Drama is defined as an educational space and tool allowing the development of different Areas in the Spanish National Curriculum, such as Art, Physical Expression or Language and Literature. Moreover, it has been shown to be a powerful instrument for developing social skills and education in ethical values, owing to its strong interpersonal and relational character. In this work our aim is, firstly, to try to clarify and differentiate the extensive and sometimes wrongly used terminology relating to Drama in Education. Secondly, we will describe the set of contributions of drama to the official curriculum, in particular in Primary School, in which the authors have developed most of their research in this field. Finally, we will go into the question of the place that Drama should take in the curriculum.

With this article we want to make a contribution to the progress of the theoretical framework of drama in education.

Key words: drama, integrated model, education in ethical values, social skills, working group.

\section{SOMMAIRE}

La dramatisation est définie comme un espace et un outil éducatif permettant de développer le curriculum scolaire dans de différents domaines tels que l'éducation artistique, l'expression corporelle, la langue ou la littérature. En plus, par son caractère relationnel et interpersonnel, il est clair qu'il s'agit d'un outil puissant pour le développement des habilités sociales et l'éducation en valeurs. Dans cette étude, on cherche en premier lieu, à éclaircir et différencier la vaste et confuse terminologie concernant l'emploi de la dramatisation à l'école. En deuxième lieu, on fera la description des apports de la dramatisation au curriculum scolaire, en particulier à l'école primaire où l'auteur a mené la plupart de ses recherches. Finalement, on traitera la question -toujours présente- du lieu que la dramatisation doit occuper dans le curriculum scolaire.

Avec cet article, on veut contribuer au progrès de l'élaboration d'un Corpus théorique sur la dramatisation dans l'éducation.

Mots clés: drame (dramatisation), modèle intregrée, éducation en valeurs, habilités sociaux, travail en groupe.

La educación tiene el doble poder de cultivar o de ahogar la creatividad. El reconocimiento de sus complejas tareas en esta materia es una de las tomas de conciencia más fecunda de la psicopedagogía moderna. Estas tareas pueden enunciarse así: preservar la originalidad y el ingenio creador de cada sujeto sin renunciar a insertarle en la vida real; trasmitirle la cultura sin agobiarle con modelos prefabricados; favorecer la utilización de sus aptitudes, de sus vocaciones y de su expresión propia sin fomentar su egotismo; estar apasionadamente atento a la 

DRAMATIZACIÓN Y EDUCACIÓN: ASPECTOS TEÓRICOS

especificidad de cada ser sin descuidar que la creación es, también, un hecho colectivo (Faure, 1972, 229).

\section{INTRODUCCIÓN}

Nos referimos al teatro como un fenómeno personal y social. Ucar (1992) explica que es un fenómeno personal al ser un elemento apropiado para el descubrimiento, desarrollo y crecimiento de la propia persona. Y lo es también social pues el acto teatral es, ante todo, un acto de comunicación, mediante el cual un grupo de personas comparte una determinada realidad en un momento dado del espacio y del tiempo. Los dos aspectos se solapan dentro del teatro y para ambos puede resultar un valioso elemento de dinamización y progreso humano.

Las potencialidades que, en este sentido, presenta el teatro han conducido a que en los últimos años esté más presente en los programas y planes de formación del currículum escolar con fines educativos, adoptando la forma de dramatización en edades infantiles. Cada vez es además mayor la importancia que adquiere como metodología la formación personal y social en relación con las técnicas dramáticas.

Desde la educación, la dramatización se presenta como un instrumento a desarrollar con el fin de rentabilizar sus capacidades respecto a una mejor formación de las personas, tanto en la perspectiva individual como social. A lo largo de este trabajo iremos fundamentando por qué y cómo puede generar la actividad dramática las habilidades sociales necesarias para el desarrollo de la comunicación, la expresión y la creatividad.

Hemos definido el teatro como práctica socio-personal y como medio de comunicación. Ambos tipos de prácticas implican que hay algo en la experiencia teatral que, al ponerse en común, se comparte, y esto significa participación física, psicológica y emocional por parte de quienes intervienen en el acto teatral. Sin duda, se trata de una actividad compleja donde entran en juego diversos planos fundamentales de la persona. El teatro se encuentra, por tanto, centrado en el hombre, y para el hombre en general, pues es válido para todas las etapas de su desarrollo. En cada etapa tendrá unos objetivos determinados, un estilo específico de desarrollarse y unas técnicas adecuadas con relación al momento evolutivo. De esta manera, el objetivo del teatro debe ser enriquecer al hombre en su desarrollo como persona, y la mejor forma de hacerlo es implementando su capacidad de relación con el mundo sociocultural que le rodea, haciendo que descubra y aprenda el mayor número de registros comunicativos posibles.

Por otro lado, siendo conscientes de que el campo de la creatividad ha ido siendo desarrollado intensa y ampliamente en las últimas décadas, y sin pretender en este trabajo realizar una contribución al mismo, hemos de señalar la estrecha relación entre el aprendizaje creativo y la dramatización. Entendemos la capacidad creativa como posibilidad de ser desarrollada por todos; quedan atrás las creencias de que "sólo los genios" eran creativos, los cuales poseían un don que les ayudaba a inspirarse en momentos casi mágicos. Así, la creatividad, como capacidad, se abre 
al mundo de la educación (García Carrasco, 1982). La creatividad se comprende como un proceso evolutivo, no espontáneo y, por tanto, al que pueden acceder todos las personas. No obstante, es cierto que, aún hoy, aquellos con tareas docentes suelen seguir adoptando determinadas posiciones acerca de qué alumnos son más creativos, y qué actividades lo son o no. Seguramente que sus intervenciones están influenciadas por esas concepciones, aunque en algunos casos no se puedan fundamentar objetivamente (Dillon, 2001).

Maslow indica, entre los supuestos teóricos de su modelo de la creatividad, que todo hombre es creativo en la medida que tiende a realizar su potencial, y que sólo con el pleno desarrollo de sus potencialidades la persona llega al máximo de su humanidad (Maslow, 1987). Compartimos esta idea. Por tanto, podríamos decir que la creatividad no es una habilidad cualquiera, sino que es necesaria para que el individuo pueda desarrollarse como persona ${ }^{1}$. Éste debería ser uno de los fines de toda educación, no sólo la formal ${ }^{2}$, sino también de la educación no formal y la informal.

En otras ocasiones hemos planteado la deficiente atención que la escuela, como conjunto, presta al desarrollo de la creatividad:

¡Cuántos docentes, a veces sin poder dar explicaciones racionalmente elaboradas, la rechazan [la creatividad], no la aceptan, al menos, inicialmente! ¿Es el temor a la innovación? ¿Es el temor inicial a la ignorancia de algunos procedimientos? ¿O es el temor a perder el estatus profesional con el que hasta ese momento se sentían seguros o estables? (Núñez Cubero, 1998, 71).

Uno de los espacios naturales que pueden favorecer la creatividad en la educación es aquel en el que utilizamos algún lenguaje artístico para el aprendizaje, por la estrecha relación entre la creatividad y el arte (García Carrasco, 2004), aunque ello no supone que las materias artísticas constituyan el único sitio para el aprendizaje creativo en la escuela ${ }^{3}$. Creemos que la dramatización, en cuanto que lenguaje artístico, ofrece unas facilidades naturales para este propósito, siempre y cuando se sepan aprovechar, y formar a los docentes para que ello sea posible (Núñez Cubero, 1979).

${ }^{1}$ En este mismo sentido, autores como BorTHwICK (1982) no conciben el proceso educativo desligado de un proceso a su vez creativo: "La aptitud creadora es inherente al proceso educativo, pues conduce al individuo no sólo a realizar nuevas asociaciones para integrar objetivos en un todo creador, sino también a saber manipularlos de manera creativa activando su mente y desarrollando sus potencialidades" (BORTHWICK, 1982, 27).

${ }^{2}$ Como aparece recogido en la LOGSE y en la LOCE, cuando se hace referencia al desarrollo integral de la persona (NAVARRO, 2005).

3 Más allá de lo que pueda ser la ubicación de la dramatización en el área de Educación Artística, la dramatización se nos presenta en la educación como un medio de aprendizaje para aplicar a cualquier materia curricular. Éste es uno de los puntos principales que querríamos desarrollar en lo que sigue. 
No hemos de olvidar que el desarrollo de la creatividad en el niño forma parte de nuestro sistema educativo y que éste no debe ser reducido a unas horas de trabajo en creatividad en el aula, sino que, por el contrario, puede impregnar todo el currículum escolar.

\section{APROXIMACIÓN AL CONCEPTO DE DRAMATIZACIÓN}

\subsection{Teatro y dramatización}

Cuando se revisan textos que ponen en relación ámbitos educativos y teatrales observamos que la mayoría de los autores definen como muy parecidos conceptos diferentes, aunque relacionados ${ }^{4}$, tales como teatro, teatro infantil, teatro de niños, teatro para niños, teatro escolar, taller de teatro, espectáculo, drama, juego dramático, improvisación, juego simbólico, representación de papeles, libre expresión...; o utilizan palabras diferentes para sinónimos casi perfectos: dramatización, juego dramático, expresión dramática. Asimismo, verbos como actuar, representar o interpretar señalan, en muchos casos sin diferenciar, distintas acciones de una persona ante un papel dramático. La elección de un término u otro dependerá en ocasiones del país en el que ésta se realice. Por ejemplo, Motos y Tejedo $(1996,13)$ explican el origen de los siguientes términos: el "juego dramático" procede de los países franceses, la "improvisación" de fuentes italianas relacionadas con la Commedia dell'Arte y la "dramática creativa" o "drama en educación" es un término más utilizado por los países anglosajones. En España, ha sido propuesta la "dramatización" como la palabra comúnmente utilizada en el ámbito educativo, pues ha sido con este término como se ha referenciado en diversas leyes educativas. En un principio la Ley General de Educación del 1970, ubicando la dramatización y el teatro infantil en el área de expresión, como parte de la Educación Artística. Esta nueva incorporación fue gracias, entre otras realidades, al apoyo encontrado en el Movimiento de Renovación Pedagógica y en la Escuela Activa. Posteriormente, en los programas renovados de 1981, la dramatización vuelve a aparecer dentro del área de Educación Artística para Preescolar y el Ciclo Inicial bajo el epígrafe "La Dramatización y otras actividades afines". Será en la LOGSE cuando la dramatización se reconozca como ámbito propio dentro del área de Educación Artística, junto a la Plástica y la Música en la Educación Primaria. No obstante, en realidad, debemos apuntar que tampoco existe un consenso mayoritario sobre qué término es el más adecuado. Veremos que sus funciones en la educación rebasan aquellas que se refieren a lo artístico, y que tampoco existe un consenso sobre su lugar en la educación. Vamos por ello a definir en este punto los conceptos genéricos que se

\footnotetext{
${ }^{4}$ Este elevado número de denominaciones, así como la utilización imprecisa de términos bien diferentes para una misma finalidad, provoca confusión. Coincidimos con Tejerina $(1994,121)$ cuando afirma que "esto obedece a la falta de claridad conceptual, la diversidad de métodos y a que no existe un cuerpo doctrinal coherente".
} 
relacionan con la dramatización y el teatro en la escuela, para así poder diferenciarlos correctamente .

En primer lugar, aclaremos el concepto teatro infantil, para diferenciarlo definitivamente de dramatización. Observamos que con la denominación teatro infantil se expresan al menos tres realidades diferentes: el teatro para niños es el que preparan los adultos para los niños, que pasan a ser espectadores; el teatro de los niños es el que piensan, dirigen y representan los niños y que, supuestamente, no debería tener público, por lo que no debería llamarse teatro; y teatro mixto, pensado, escrito y dirigido por el adulto y representado por los niños (Cervera, 1996), que suele ser el más común en el mundo escolar. A nuestro modo de entender, esta última modalidad teatral corre el peligro de convertirse en un proyecto para agradar a los padres en la fiesta final de curso, sin atender a las necesidades de los niños, sino más bien a las de los adultos, que son completamente diferentes (gusto por la estética, manifestado en lo bien hechos que estén los disfraces, el escenario, orgullo por el tiempo que sus hijos reciten textos...), llegando a casos en los que se selecciona a los niños más agraciados para darles los papeles principales ${ }^{6}$.

Por otro lado, Tejerina (1994) nos advierte del peligro de ridiculizar el teatro para los niños cuando éste se dedica a imitar sin más el mundo de los niños, a tratar de simplificar los grandes temas de los adultos o a la moralización explícita y abusiva que aparece con frecuencia en la literatura para este tipo de teatro. No obstante, y al mismo tiempo, esta autora reconoce que el teatro profesional para niños está en ascenso internacionalmente. Especialmente a partir de la década de los 70 , aumentan considerablemente las compañias profesionales, los Congresos y Simposios, Festivales... También en nuestro país se va consolidando tímidamente esta realidad; prueba de ello son los Festivales Internacionales de Titeres realizados en Bilbao, Barcelona, Sevilla, Segovia... o las Semanas Internacionales de Teatro para Niños que organiza desde 1985 la asociación Acción Educativa de Madrid, la feria de Títeres que se celebra en Gijón y un amplio abanico de iniciativas promovidas en otras localidades.

${ }^{5}$ Para un mayor desarrollo de este apartado, recomendamos la lectura del tercer capítulo de la tesis doctoral del prof. Tomás Motos (1992) de la Universidad de Valencia, titulado: "Las técnicas dramáticas: Conceptualización". En él encontramos un laborioso trabajo y esfuerzo de organización de las diversas técnicas dramáticas, así como su explicación.

${ }^{6}$ La siguiente cita recoge el mismo sentir: «El teatro espectáculo tiene como finalidad la representación. [...] Aquí hago hincapié en las "fiestitas escolares" [...] En ellas, se usa a los chicos más hábiles o menos introvertidos para recitar de memoria (textos cuyo contenido generalmente desconocen), y a chicos tensos y sufrientes, para ser observados por padres orgullosos de lo bien que les queda el disfraz que les compraron o les hicieron, y a maestros que cumplieron con lo ordenado por la dirección. Con estas actitudes antipedagógicas el chico actúa sin jugar, sin ser parte de un proceso, sin crecer" (VEGA, 1981, 15).

7 Para profundizar más en este análisis de la realidad del teatro infantil, recomendamos el espacio que dedica Tejerina (1994) en su libro a este tema (pp. 9-25). 
Motos (1992) sintetiza en el Cuadro 1 las diversas técnicas dramáticas según sus condiciones de aplicación, lo cual muestra la complejidad del concepto al que nos acercamos.

Cuadro 1. Extracto del cuadro Técnicas Dramáticas (Motos, 1992, 50)

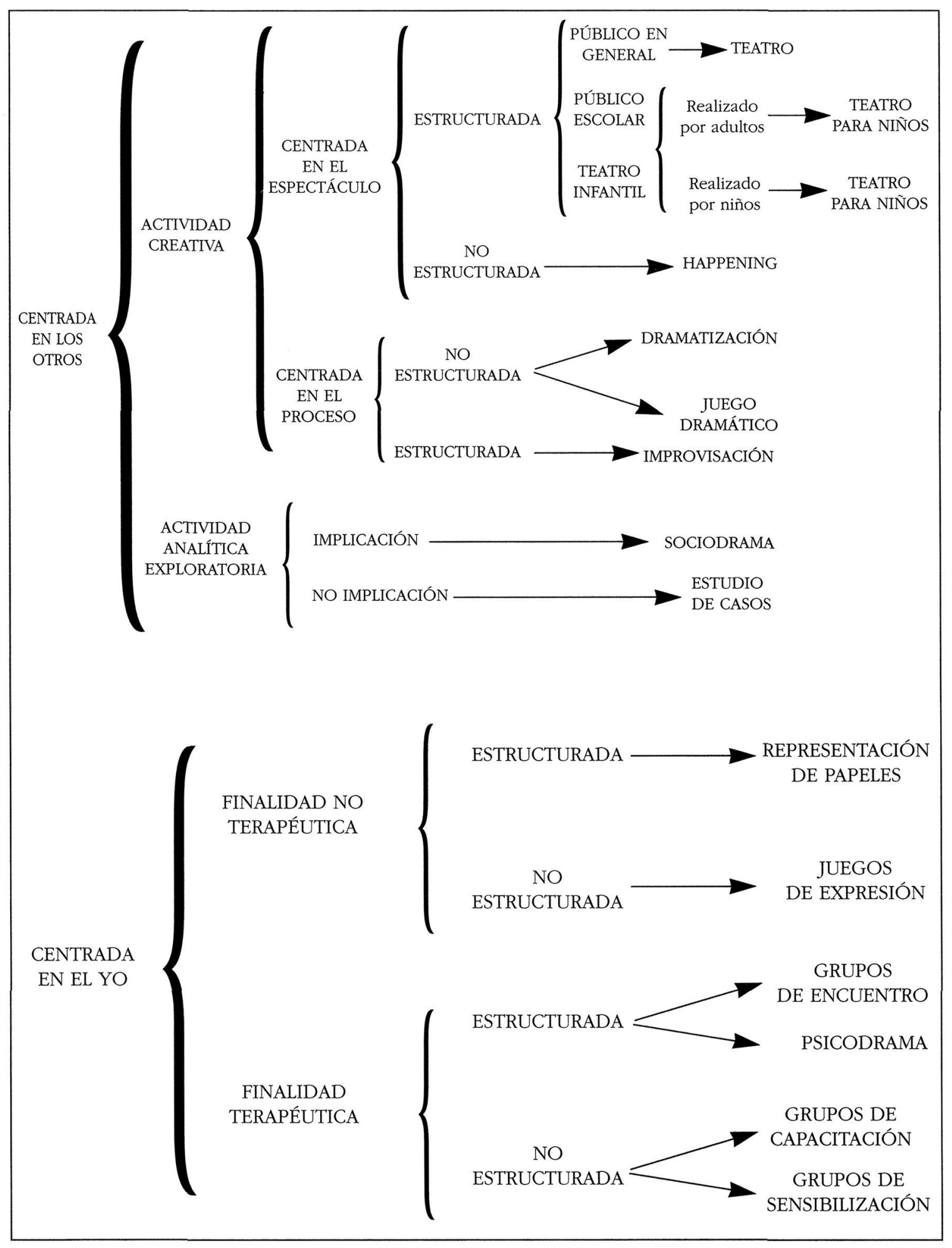




\subsection{Dramatización y juego dramático}

Los juegos, especialmente en niños y jóvenes, toman a menudo la forma de teatro, donde el propio cuerpo es el instrumento de investigación creativa, medio de expresión y comunicación. El término más genérico para denominar este tipo de juego es juego dramático ${ }^{8}$. En España, hemos incorporado este término como sinónimo de dramatización, al ser ambos una forma de expresión dramática estructurada y cuyo interés reside en el proceso, más que en el producto. Su materia propia es la acción, en la búsqueda de la mejora de la comunicación y la potenciación de la creatividad. Por medio de ellas buscamos que el niño desarrolle sus capacidades perceptivas y expresivas, con el fin de que encuentre y potencie la expresión de sí mismo en relación con los otros y con el mundo. El juego supone un auténtico medio de aprendizaje, un medio por el que los niños exploran activamente diversas experiencias en diferentes casos. "La situación de juego proporciona estimulación, variedad, interés, concentración y motivación" (Moyles, 1990, 22). Por ello, el juego dentro de la escuela motiva necesariamente un aprendizaje distinto. Éste conduce de modo natural a la creatividad porque, en todos los niveles lúdicos, los niños se ven obligados a emplear destrezas, tanto físicas como mentales, y procesos que les ofrecen oportunidades de ser creativos, a la vez que ayuda a los participantes a lograr una confianza en sí mismos y en sus capacidades. En definitiva:

El juego es el modo que tiene el niño de pensar, probar, relajarse, trabajar, recordar, competir, investigar, crear, ensimismarse [...]. Si el juego es la manera normal que tiene el niño de vivir, constituye en tal caso el mejor modo de enfocar cualquier forma de educación (Slade, 1978, 54).

Pero, ¿hasta qué punto no consideramos en muchas ocasiones el juego en los niños como una actividad secundaria, que en todo caso debe tener lugar una vez terminado su trabajo escolar? Con demasiada frecuencia el juego se ha utilizado para referirse a algo más bien trivial y carente de seriedad, el extremo opuesto del trabajo, desaprovechando las posibilidades didácticas del mismo. Un uso educativo del juego puede favorecer el desarrollo integral del sujeto, ya que la capacidad lúdica, como cualquier otra, se desarrolla articulando las estructuras psicológicas globales, no sólo cognitivas, sino afectivas y emocionales, con las experiencias sociales que cada uno posee.

${ }^{8}$ Es una forma de dramatización que incluye el juego espontáneo y en la que el adulto coordina a un grupo de niños que inventa, crea e improvisa a partir de temas y personajes elegidos por ellos mismos, sin la presencia de espectadores (EINES y MaNTOVANi, 1980; MANTOVANi et al., 1993).

(C) Ediciones Universidad de Salamanca

Teor. educ. 19,2007 , pp. 225-252 
Por otro lado, el juego dramático es una forma concreta del juego infantil que requiere de una edad más avanzada que la del juego simbólico9 ${ }^{9}$. Para una mayor comprensión veámoslo en el siguiente cuadro elaborado por Motos (1996). En él aparecen dos vectores: espontaneidad-elaboración técnica, que se refiere al grado de estructuración y libertad que una forma dramática posee. Aquí aparecerían desde actividades que se expresan con plena espontaneidad hasta aquellas otras que se encuentran sometidas a una serie de reglas fijas y muy estructuradas. El otro vector, el proceso lúdico-producto artístico, se refiere a la finalidad con la que utilizamos las diversas formas dramáticas, al tiempo que las relaciona con las etapas educativas: desde las lúdicas, cuya finalidad es la mera diversión, hasta el producto artístico finalizado, elaborado para una finalidad comunicativa o estética.

En una lectura vertical de este cuadro con el que le sigue, podemos relacionar las edades y etapas escolares en las que, aproximadamente, aparecen las condiciones adecuadas en el alumno para trabajar cada forma dramática.

CUADRO 2. LAS FORMAS DRAMÁTICAS Y DESARROLLO EVOLUTIVO DEL NIÑO (Motos, 1996, 127)

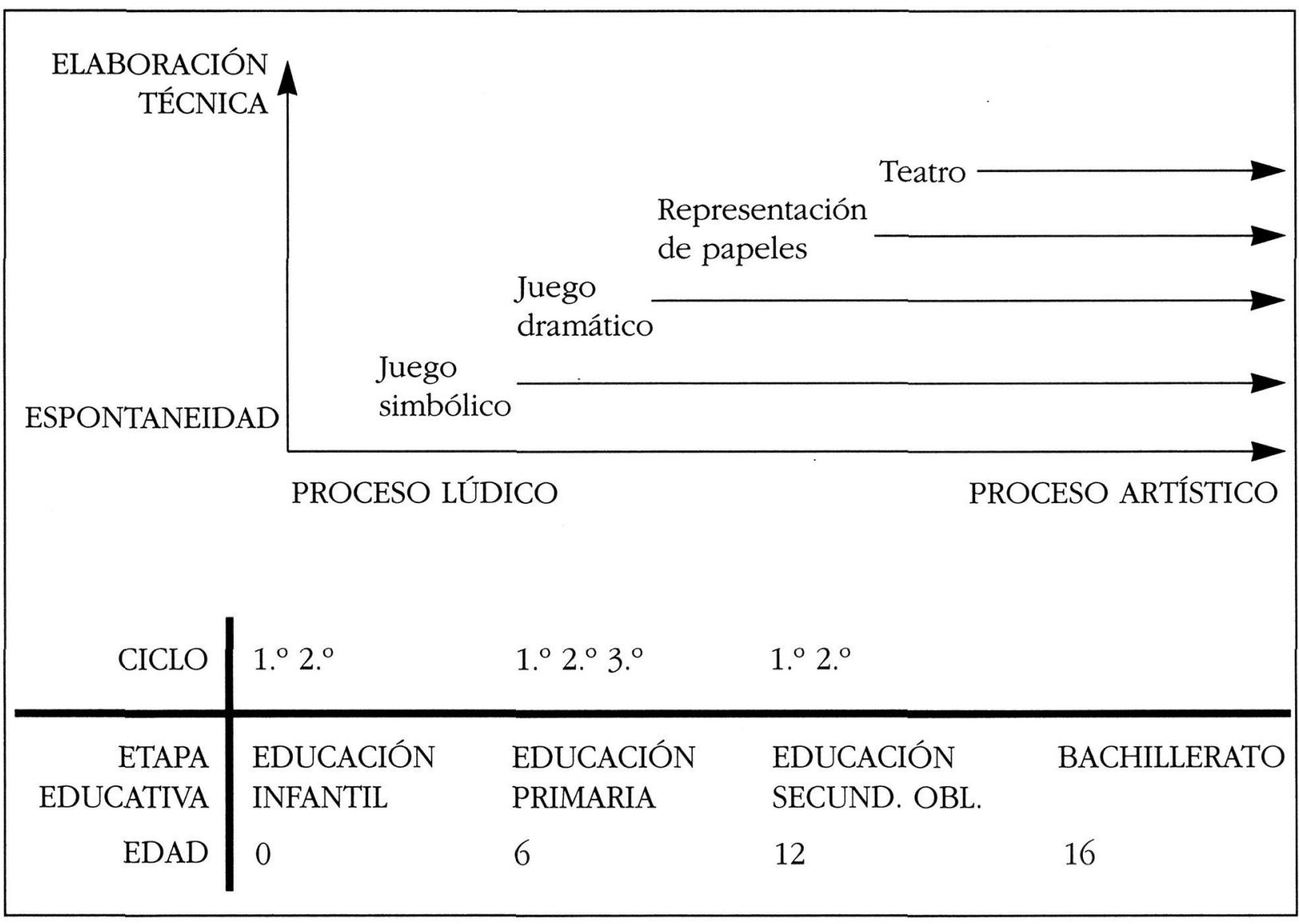

9 Tejerina (1994) explica que los juegos simbólicos espontáneos se sitúan en el inicio de la expresión dramática, mientras que la dramatización o juego dramático correspondería a la siguiente etapa, finalizando esta educación con el teatro formalizado. 
En definitiva, en el uso pedagógico de la dramatización hemos de tener muy en cuenta las diferentes fases de la evolución de las formas dramáticas en el desarrollo evolutivo del niño, que van desde el juego al teatro, como indica Neelands en la cita que sigue:

El tipo de drama que estamos acentuando es un punto sobre un continuo que tiene su génesis en el juego infantil y su máximo desarrollo cultural y personal en la forma artística del teatro. En otras palabras, el maestro está intentando conducir la experiencia de juego existente en los niños a las formas menos familiares del teatro, en orden a centrar y profundizar la experiencia de aprendizaje de éstos (Neelands, 1984, 26).

\subsection{Drama y dramatización}

Lejos de querer hacer de este punto un tópico a tratar cuando pensamos sobre el drama en la educación, consideramos que es necesario seguir dando argumentos de la conveniencia de utilizar un término común. En una primera aproximación, podríamos afirmar que el vocablo no había de importarnos, siempre y cuando coincidiésemos en los objetivos de esta actividad: el uso del recurso dramático para el desarrollo personal y, especialmente, social de la persona, potenciándoles sus capacidades expresivas. Para ello, utilizaríamos múltiples recursos, así como lenguajes que aglutinaríamos bajo el nombre de dramatización, a saber: el juego, la expresión corporal, la música, la plástica, la literatura, la improvisación, relajaciones... Como hemos indicado, en España, la LOGSE decidió incorporar a la Educación Artística el ámbito de la Dramatización en la Educación Primaria; ello reforzó el uso del término dramatización para referirnos a esta realidad educativa. Pero, a la vez, seguíamos dirigiéndonos a ella como «juego dramático", "expresión dramática", "drama". Todos ellos parecían ser considerados sinónimos en cuanto que los utilizábamos para un mismo objetivo. Diversos autores como Motos, Tejerina o Mantovani, en diferentes trabajos, manifestaban que la gran variedad de términos con los que nos solíamos referir a este ámbito obedecía en gran medida a la falta de claridad, muchas veces reflejo de la necesidad de seguir avanzando en la consolidación de este espacio educativo, también a nivel conceptual. Posteriormente leíamos: "No quiero decir con esto que una terminología sea mejor o peor que otra, sino que están nombrando cuestiones diferentes. Todas son válidas en función de sus objetivos pero en ningún caso identificables" (Bercebal, 1995, 32).

Han sido los diálogos con compañeros del campo del arte dramático, de la pedagogía o con los estudiantes de magisterio, los que nos han hecho entender que cuando nombrábamos "dramatización", la otra persona entendía la acción de dramatizar, bien un texto, una historia, una acción... quedando reducido al uso de una técnica concreta el complejo campo al que nos estábamos refiriendo con la dramatización. Esta realidad difiere de la anglosajona, en la que el concepto «drama en la educación" goza de un reconocimiento común y asociado a este otro espacio 
más amplio y complejo. Inglaterra cuenta con una extensa bibliografía sobre drama y numerosos especialistas en la materia, tanto teóricos como prácticos. Coincidimos con Bercebal en que merece la pena que vayamos extendiendo la idea anglosajona del vocablo drama, perteneciente éste, al mismo tiempo, a nuestra lengua. Posiblemente ello impediría esa rápida asociación que hacemos a la técnica dramática "dramatizar" y facilitaría el preguntarse por su significado (Navarro, 2004). Por este motivo utilizamos como sinónimos drama y dramatización en este artículo.

\section{APORTACIONES DE LA DRAMATIZACIÓN AL CURRÍCULUM EDUCATIVO}

En este apartado vamos a tratar de desarrollar algunas de las aportaciones que el drama como herramienta educativa ha hecho y puede seguir haciendo en la educación. En gran medida son estas contribuciones las que nos llevan a defender el uso del drama en la escuela ${ }^{10}$, así como las que justifican la defensa por darle un espacio apropiado en el currículum escolar ${ }^{11}$. Nuestras investigaciones en este campo nos conducen a una confirmación de la validez de la dramatización para el desarrollo de habilidades sociales y el área Artística. Pero podemos ir un poco más allá, pues el drama se nos ha manifestado como una herramienta privilegiada para el desarrollo, además, de otras áreas curriculares.

\subsection{Elemento motivacional para el aprendizaje. El aprendizaje vivencial}

Fleming (1994, 37) expresa la naturaleza motivadora del drama con las siguientes palabras: “Una explicación más convincente de la fuerza motivadora del drama es que éste aprovecha la tendencia a jugar, la cual presenta su mayor fuerza en los niños de edades infantiles, pero persiste en la adolescencia y probablemente en toda la edad adulta". Esta tendencia al juego les sirve, al mismo tiempo, a los niños para entender el mundo, como sigue explicando el mismo autor: "Tanto en la historia del teatro como en la historia del juego personal en la forma de

${ }^{10}$ Para ampliar esta cuestión, recomendamos el desarrollo de este tema hecho por T. Motos y A. NAVArRo (2003) bajo el título "El papel de la dramatització en el currículum", publicado en Articles, 29, 10-28.

11 En NAVARRO (2005) aparece un extenso análisis del lugar distinto que LOGSE y LOCE otorgan a la dramatización. Básicamente, la LOGSE interpreta el valor de la dramatización como ámbito dentro de la Educación Artística, de manera que, junto a la Música y la Plástica, constituyen los espacios mediante los cuales el niño desarrollará sus capacidades y aptitudes frente a lo artístico, lo creativo y lo estético. Por otro lado, la LOCE, siguiendo más de cerca ciertas corrientes de la tradición inglesa, defiende la dramatización como herramienta educativa para el desarrollo de otras áreas curriculares, como son la Educación Física, la Lengua o la Literatura. Como indicaremos más adelante, nuestro enfoque se centrará en el denominado Modelo Integrado, que considera que ambas facetas han de conjugarse para extraer de la dramatización todo su potencial pedagógico. 
presentación dramática, hay una fuente común de recreación placentera y un significado sobre el sentido que tiene el mundo" (Fleming, 1994, 38).

La dramatización ha de poseer siempre un componente lúdico, aunque en ella incorporemos un trabajo sobre cuestiones de gran trascendencia; el juego permite introducir al niño a experimentar las ideas de una forma diferente.

Wagner $(1998,9)$ nos explica esa capacidad del niño para jugar y explorar al mismo tiempo:

Los niños traen consigo a la clase una habilidad universal para el juego, para comportarse "como si", muchos niños se meten espontáneamente dentro de un juego similar al dramático como si fuesen jóvenes... Los maestros de drama en educación reconocen y valoran esta habilidad universal de los niños para utilizarla en la clase y usarla como un recurso educativo. Los niños tienen una oportunidad para jugar con varias opciones del comportamiento, generando una serie de posibilidades y reflejando las consecuencias sobre las mismas -todo sin tener que experimentar alguna vez los resultados de sus acciones como hacen en la vida real-.

Por otro lado, la dramatización supone un espacio que provee seguridad para la exploración de ideas. Tejerina $(1997,75)$ explica esta sensación de seguridad porque para ella:

...el juego funciona como una estrategia de desbloqueo y de liberación expresiva, al tiempo que crea un espacio para la creatividad, porque en él se eliminan lo que Wallach y Kogan $(1983,84)$ llaman obstáculos motivacionales, como el temor a ser juzgados, la preocupación por la opinión de los demás sobre la competencia y el rendimiento personal, la autocensura respecto del propio éxito o fracaso. El juego acaba siendo un lugar en el que nos atrevemos a ir más allá de lo conocido porque las consecuencias no son frustrantes, y esto es lo que lo convierte, según demuestra Bruner (1984, 212-213), en un poderoso medio para la exploración y el aprendizaje creativo. El juego es el reino de la libertad y de la creatividad, el ambiente idóneo para el descubrimiento y el hallazgo. En su estudio "Realidad y juegon (1982), el psicólogo Winnicott afirma algo que me parece definitivo: En él, y quizá sólo en él, el niño o el adulto están en libertad de ser creadores.

Es éste uno de los aspectos más importantes que aporta el trabajo desde la expresión dramática con el niño, porque provee un espacio que le hace sentirse seguro, ya que todas las ideas son incorporadas por el grupo, sin que existan ideas buenas y malas. Por otro lado, el niño sabe que él está haciendo "como si" fuese otra persona y, por tanto, se siente con mayor libertad a decir o lanzar propuestas de actuación.

La motivación hacia el aprendizaje desde el drama aumenta pues éste dota al aprendizaje de un contexto concreto que permite reconstruir los conceptos abstractos, fuera del alcance de la experiencia personal de cada niño, desde situaciones particulares. Ésta es la experiencia de autores que como Neelands (1984) utilizan el drama en sus clases: 
Nosotros percibimos que los niños aprenden mejor construyendo y haciendo, y el drama les provee un recurso físico y concreto para examinar los objetivos que, de lo contrario, continuarían por fuerza abstractos e inaccesibles. Un niño necesita reconstruir el significado abstracto por medio de una forma a la que pueda hacer frente. Cuando los niños reconstruyen, cualquiera de ellos construye elaborando su propia comprensión (Neelands, 1984, 25).

\subsection{Desarrollo de la creatividad}

Como señalábamos, el drama constituye un espacio desde el que fomentar la creatividad, pues, en esencia, desarrolla todas y cada una de las claves de ésta, a saber: la representación, la originalidad, la productividad, el pensamiento creativo o la resolución de conflictos, el aprendizaje creativo, y la vinculación afectiva con el medio (Beetlestone, 2000). La propia naturaleza de la dramatización presenta características que potencian la creatividad, ya que "la esencia natural del medio dramático es un acto de liberación de la imaginación" (O'Neill, 1995, 159). Al mismo tiempo, el drama ofrece la construcción de ambientes y de roles imaginados por el grupo, que acaban convirtiéndose en una experiencia real para los alumnos, que probarán las consecuencias de diferentes comportamientos y acciones.

Son éstos y otros motivos semejantes los que llevan a diferentes autores en sus estudios sobre creatividad en relación a la dramatización, a resialtar el lenguaje dramático como un medio eficaz para potenciar los procesos creitiviss en la educación (Motos, 2003). Entre ellos, encontramos a Díez (1980), qu afirma: "Las dramatizaciones escolares son, tal vez, la forma más completa de exprésión creadora para el niño" (Díez et al., 1980, 83-84); Cervera (1991) elabora específicamente cómo la expresión dramática desarrolla la creatividad en el currículum escolar en el Manual de Creatividad. Por otra parte, Torrance y Myers (1976) desarrollan en su obra los diferentes aspectos a tener en cuenta para una enseñanza creativa y la importancia de la misma para la sociedad y la educación. En una de sus propuestas de los métodos de enseñanza posibles para desarrollarla, proponen el sociodrama " ${ }^{12}$ "como proceso de la solución creativa de problemas. [...] El objetivo consiste en examinar un problema de grupo social mediante métodos dramáticos» (Torrance y Myers, 1976, 116) ${ }^{13}$.

12 Los principios generales del sociodrama fueron elaborados por MORENO (1946), y perfeccionados posteriormente por HAAS (1948), HANSEN (1948), KLEIN (1956) y otros.

${ }^{13}$ Los pasos propuestos por estos autores para aplicar el sociodrama en la resolución de conflictos son los que siguen: definición del problema, plantear una situación (conflicto), reparto de papeles, instrucciones finales y puesta en situación de actores y espectadores, desarrollo de la situación, interrupción de la acción, discusión y análisis de la situación y la conducta, planeamiento para probar las ideas sobre nuevas conductas. Si bien es cierto que la dramatización en la educación no es exclusivamente sociodrama, sí que estas pautas de actuación son utilizadas en muchas ocasiones cuando interesa abordar desde el grupo problemas ante una situación ficticia determinada. 
El drama es un medio privilegiado que desarrolla la creatividad, ya que requiere de la elaboración de nuevas situaciones y respuestas utilizando los recursos lingüísticos, corporales, musicales, gestuales, etc. El desarrollo creativo personal es fruto en parte de la creación de contextos creados por la práctica de la dramatización. Se pueden marcar pasos y procedimientos seguros y fiables para estimular los procesos creativos. Es decir, el desarrollo de la creatividad mediante la dramatización en el aula no es fruto de una improvisación constante o falta de planificación por parte del profesor ${ }^{14}$. Es evidente desde el análisis de nuestras experiencias que cada sesión de dramatización tiene una estructura, un modo de proceder concreto. La estructura del drama en la educación es una de las líneas de investigación candente en el ámbito anglosajón.

\subsection{Desarrollo del área Artística}

Es éste un apartado que guarda una íntima relación con el anterior, pero que expresamos separadamente pues el área Artística aparece como espacio curricular independiente en las distintas legislaciones educativas. En efecto, uno de los objetivos que Sánchez Méndez (1999) apunta sobre la Educación Artística hace referencia al desarrollo de la creatividad, pues los instrumentos que utilizamos en ella (plásticos, dramáticos y musicales) trabajan con la propia expresión del niño. La realización de trabajos en la educación artística es fruto de unas cualidades perceptivas y de autoexpresión, con una fuerte carga subjetiva y personal, que nos conduce a afirmar que se trata de procesos más complejos que la simple adquisición de destrezas. No obstante, aún está muy extendida entre el profesorado la asociación de la educación artística con la adquisición y práctica de destrezas artísticas. Siendo fácil encontrar ejemplos verídicos como el que sigue: una profesora de Educación Infantil le arruga y le tira a una niña su dibujo de la paloma de la paz porque se le ocurrió colorearla con los colores preferidos de la profesora en práctica para regalársela y no blanca con el pico naranja.

La extraordinaria capacidad de creación de contextos que posee la dramatización permite extraer de cada niño toda su capacidad expresiva y creativa. Además, coincidimos con el matiz social que Vygotski $(1996,37)$ otorga a cualquier proceso de creación: «Todo inventor, por genial que sea, es siempre producto de su época y de su ambiente" y sigue citando a Riband ${ }^{15}$ "por muy individual que parezca, toda creación encierra siempre en sí un coeficiente social".

\footnotetext{
${ }^{14}$ Podemos afirmar que la escasa práctica de la dramatización en los centros escolares guarda una estrecha relación con la casi nula formación inicial del profesorado que los futuros maestros reciben en nuestras Universidades (NAVARRO, 2003). Este hecho, que consideramos grave y que necesitaría ser corregido, hace que, a pesar de que la dramatización posee un cuerpo elaborado de contenidos, estrategias y técnicas para su aplicación, se imposibilite su puesta en marcha más allá del buen hacer de ciertos maestros convencidos del fuerte potencial pedagógico del uso de la dramatización con niños.

15 Citado en Vygotski $(1996,38)$.
} 


\subsection{Desarrollo de las habilidades expresivas y comunicativas}

Motos (1992) y Moreno (1999) muestran en sus trabajos de tesis doctorales cómo el drama favorece el enriquecimiento de las capacidades expresivas y lingüísticas. Utilizan la dramatización como herramienta didáctica para el aprendizaje de la Lengua, obteniendo resultados excepcionales del enriquecimiento del vocabulario o del uso del lenguaje en diversos contextos. Es en Inglaterra donde descubrimos un profundo desarrollo del uso del drama en esta área. Recordemos nuevamente que es ésta precisamente una de las orientaciones fundamentales que la LOCE planteaba para la actividad dramática en la escuela ${ }^{16}$. En este sentido, se hace patente la necesidad de que en España tengamos la posibilidad de desarrollar con amplitud el papel del drama en la lengua, que sirva como orientación a los maestros, que además habrán de ser formados para ello ${ }^{17}$.

\subsection{Habilidades sociales y resolución de conflictos}

El hecho de que la dramatización requiera constantemente un trabajo en grupo aporta el aprendizaje cooperativo en la clase, desde el que aprender a trabajar con otros, respetando sus ideas y su propia forma de expresión. La dramatización va generando un sentimiento de grupo creado por la interacción de sus componentes y una comprensión de que el trabajo creativo del grupo es siempre superador al individual. Motos y Navarro (2003) relacionan este aspecto con el objetivo de desarrollar aspectos de la inteligencia interpersonal (Gadner, 1999). Además, Laferrière (1993) señala una serie de principios intrínsecos a la dramatización en cuanto que son la base previa para poder improvisar. Los consideramos muy interesantes para el desarrollo de habilidades sociales en el niño a la hora de relacionarse con los demás. Éstos son:

- Ser conscientes de la composición del grupo. Todos sus miembros tienen la misma importancia.

- Saber integrar las personas y los sucesos. No se podría imaginar el juego dramático sin una mezcla de lo personal y lo colectivo influyéndose mutuamente. Ésta es su esencia misma.

- Tener confianza en sí mismo y en los otros.

16 La recién aprobada Ley Orgánica de Educación (LOE) aún ha de concretar el desarrollo curricular, por lo que desconocemos el papel que otorgará a la dramatización. Como indicábamos anteriormente, existe una clara diferenciación entre LOGSE y LOCE en relación al uso de la dramatización en el aula.

${ }^{17}$ Somos conscientes del uso que de la dramatización se está realizando en muchos centros educativos para el aprendizaje de la Lengua Extranjera, en particular el inglés. Además, en las asignaturas sobre "Drama y Educación" que anualmente impartimos en la Universidad de Sevilla, son frecuentes las alumnas que proceden de la Titulación de Filología Inglesa. 
- Ser consciente del trabajo personal y del trabajo colectivo. Un buen trabajo personal es más enriquecedor si es canalizado en función del grupo.

- Tener capacidad de concentrarse en un rol o en una situación.

- Saber escuchar el entorno, las personas y las acciones. La escucha activa permite comprender mejor las cosas que la rutina nos impide conocer.

En este mismo sentido, la dramatización se presenta como un recurso inestimable para la educación en resolución de conflictos, en cuanto que el alumno puede encontrarse ante diversos escenarios, a veces contradictorios o conflictivos, para los que se necesitan varias alternativas para elegir y pretendemos que analicen sus implicaciones (Ferrer et al., 2003). Mediante la dramatización, el alumno explora además conscientemente estados de ánimos y sentimientos, además de las consecuencias que pueden tener sobre el tipo de respuesta que demos a un determinado problema. Esto pude constituir un espacio ideal para el trabajo de la educación emocional ${ }^{18}$ (Goleman, 1996) y de la inteligencia interpersonal. Ambos aspectos son esenciales para un desarrollo sano y equilibrado de la personalidad del niño.

Finalmente, hemos de señalar que además genera una relación no habitual entre alumno-profesor (Motos, 1995), ya que éste entra a formar parte también del juego del propio niño, aceptando sus propuestas.

\subsection{Aportaciones a otras áreas del currículum}

$\mathrm{Si}$ bien es cierto que, como hemos indicado, el drama puede tener un espacio en la educación como actividad para el desarrollo artístico, junto al resto de artes como la Música, la Plástica o la Danza, la actividad dramática también se propone como recurso didáctico para la enseñanza de otras áreas por su carácter fuertemente globalizador ${ }^{19}$. Éste incorpora múltiples lenguajes bajo la estructura dramática: musical, icónico, corporal y verbal.

Puesto que el área de Educación Física plantea la educación en aquellos aspectos afines al cuerpo y la actividad motriz, el juego es parte esencial de la misma; es más, el juego se plantea como un elemento fundamental en la Educación Primaria como recurso metodológico. Es destacable la estrecha relación de esta área con la consecución de objetivos en relación a valores y normas de convivencia,

18 Para conocer una experiencia de trabajo concreta sobre la educación emocional a través del lenguaje dramático, véase NúÑez CUBERo y Romero PÉrez (2004). En este trabajo se va describiendo la aportación que el lenguaje dramático hace al desarrollo de la educación emocional, haciendo referencia para la confirmación de algunas de las hipótesis expuestas, a la experiencia iniciada en el curso académico 2001/2002 con un grupo de estudiantes de Bachillerato, de 16 a 18 años.

${ }^{19}$ Ésta es precisamente la orientación que se le dio en la LOCE, a saber, como herramienta válida para el aprendizaje de otras áreas. 
como los hábitos de esfuerzo, el trabajo en equipo, el desarrollo de la iniciativa personal, la resolución de conflictos mediante el diálogo, el respeto en las relaciones y a las reglas de juego establecidas o la formación en la responsabilidad. Se trata, por consiguiente, de un espacio singular de interdisciplinariedad, que conecta de manera natural con las características que para la dramatización hemos ido desarrollando en los apartados anteriores.

Como ya hemos indicado, de especial relevancia son las posibilidades de la dramatización para el área de Lengua en el sentido de la búsqueda de la mejora progresiva en el uso de la lengua, explorando cauces que desarrollen a partir de ésta la sensibilidad, la creatividad y la estética. Además, el drama supone un medio privilegiado para la creación de contextos que requieren el desarrollo de las expresiones verbal y no verbal, tratando y aprendiendo a satisfacer las necesidades de comunicación en situaciones diversas.

Finalmente, y partiendo de la imperiosa necesidad del aprendizaje de lenguas extranjeras en un contexto de pertenencia a la Unión Europea, se desarrolla además la necesidad de adentrase y entender la cultura, las costumbres y las formas propias de los países que tienen estas lenguas como propias. Es destacable la importancia de priorizar en Primaria las destrezas orales, e ir incorporando gradualmente otros aspectos del funcionamiento de la lengua. Es precisamente este interés en el desarrollo de las posibilidades orales de la lengua extranjera y su contextualización en situaciones reales lo que sitúa la dramatización, de nuevo, como una importante herramienta en esta área.

4. El espacio de la dramatización en la etapa de Educación Primaria: ¿Ámbito PROPIO O METODOLOGÍA DE APRENDIZAJE?

Frecuentemente encontramos diversas posturas ante esta pregunta; por un lado, están aquellos que opinan que el currículum escolar debe tener en cuenta la alfabetización estética de los niños para una mejora de la comprensión de su propia cultura, para lo cual la educación artística constituye un lugar privilegiado. La dramatización formaría parte del currículum artístico en las escuelas. En algunos lugares como Australia o los estados de Florida o Jamaica en EE.UU. ésta tiene un espacio como materia propia al igual que otras materias artísticas. En otros países, como era el caso de España en la LOGSE, se contemplaba como ámbito del área de Educación Artística, junto a la Música y la Plástica. Por otro lado, están quienes creen que la dramatización sólo constituye una técnica útil a utilizar en diversas áreas curriculares, pero que en sí misma no tiene solidez para ser enseñada independientemente. No pocas veces hallamos estas posturas enfrentadas. Ello manifiesta diferentes modos de entender la dramatización en la educación y, a su vez, nos suele llevar a pensar en diversos perfiles de la persona que debe enseñar la dramatización a los niños. A saber, o bien un especialista formado en la disciplina del arte dramático, con la evidente dificultad que manifiesta Laferrière $(1997,59)$ : 
Puede ocurrir que los artistas tengan la tentación de utilizar sólo su competencia de artista para enseñar. Si estos últimos no son, por azar al mismo tiempo pedagogos natos, se corre el riesgo de que la mayoría de alumnos no puedan penetrar en el universo de las artes, al cual se quiere dar acceso.

O, por otro lado, un maestro generalista que esté en contacto con el resto de áreas del currículum. Esta última opción no supone menos peligro para un uso adecuado del drama si sólo hemos de confiar en la buena voluntad de éste, máxime si no ha recibido formación específica sobre las características de la dramatización en la educación.

Neelands ${ }^{20}$, para explicar cuáles son las diversas posturas surgidas en torno a esta pregunta, desarrolla diferentes modelos para relacionar la idea que tenemos del drama en la educación con el uso que hacemos del mismo. Hemos optado por ser fieles a los diagramas originales, a sabiendas que las asignaturas que en ellos aparecen forman parte del currículum inglés y no del español. Así pues, nos encontramos con: "Inglés", materia en la que se ubica el drama en la actualidad, "Artes" y "Educación personal, social y moral" (Psme). No obstante, apuntamos como carencia de los diagramas que presentamos, el hecho de que sólo se mencionen tres áreas de conocimiento en los cuadros 1,2 y 3, obviando la relación que el drama pueda tener con el resto de las asignaturas del currículum. Nos consta que el autor de estos cuadros también se refiere a otras materias en su discurso, aunque no hayan sido expresadas gráficamente. Salvando esta aclaración, los modelos que aquí se proponen son válidos para la cultura escolar española, y los consideramos de gran utilidad para facilitar la comprensión de este punto.

\subsection{Modelo Fragmentado}

En él el drama no tiene una identidad propia y, consecuentemente, tampoco un cuerpo de procedimientos, conocimientos y conceptos propios. Antes bien, éstos los adopta del área curricular desde la que empleemos dicha técnica. Por tanto, podríamos considerar que tampoco posee una aportación específica al currículum, sino que es considerado simplemente como herramienta didáctica.

${ }^{20}$ Las ilustraciones que aquí utilizamos son tomadas de los apuntes facilitados y elaborados por el Dr. Jonothan Neelands en el Máster Internacional "Drama and Theatre Education" que ofrece el Institute of Education de la Universidad de Warwick (Reino Unido) y del cual él es coordinador. Este curso acoge cada año a un grupo formado por profesionales del arte dramático, maestros y profesores de Secundaria a nivel internacional (griegos, americanos, canadienses, chinos, japoneses, africanos, irlandeses y, por supuesto, ingleses). Nosotros formamos parte de él durante los tres meses de nuestra estancia en dicha Universidad en el último trimestre del curso 02/03. 


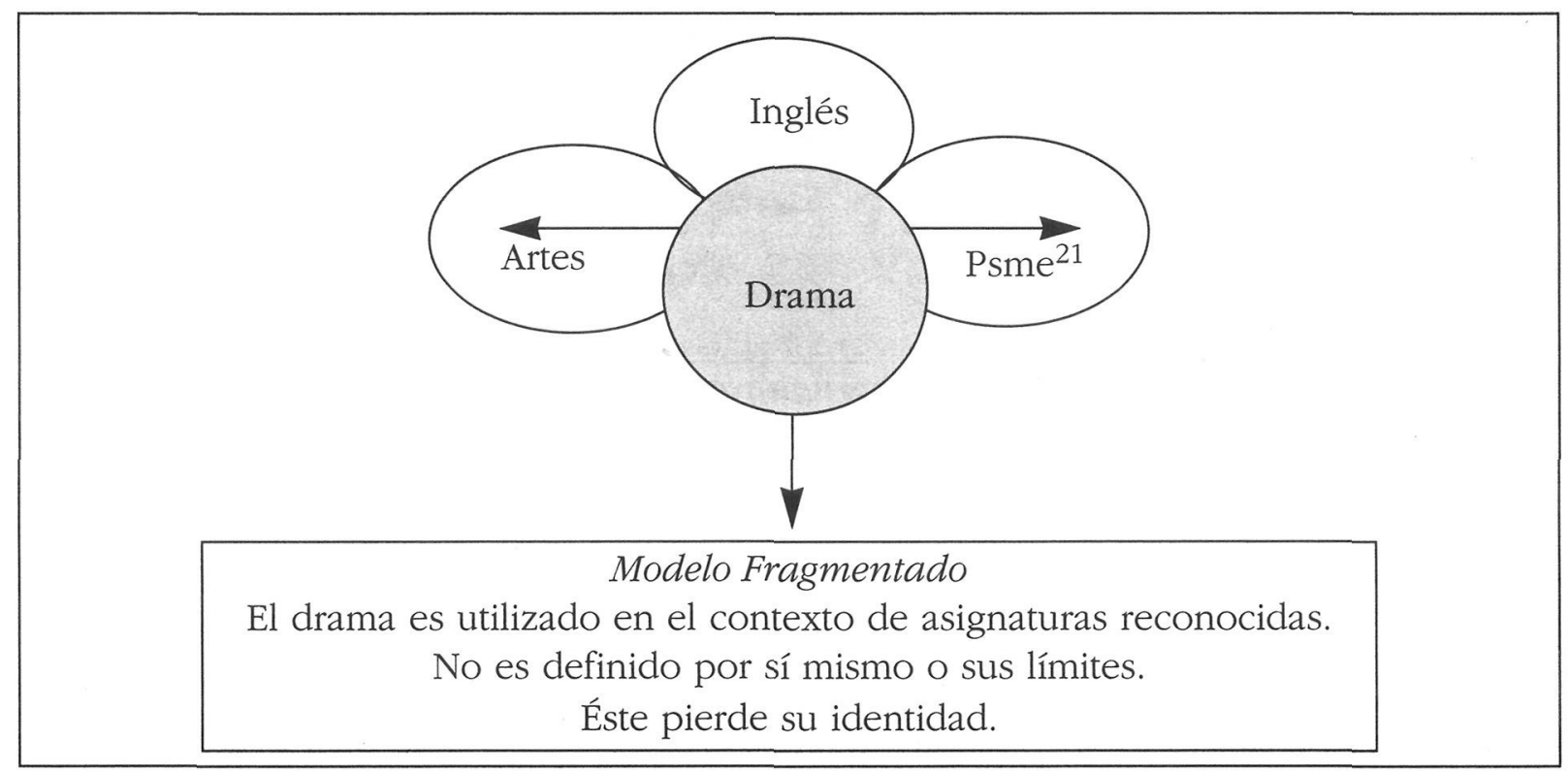

Desde este modelo, entendemos el uso que de él se hace en la escuela cuando se aplica la dramatización a la explicación de un contenido, pero sin respetar sus características, entre ellas, el aprendizaje creativo, la expresión y comunicación o la generación de un clima adecuado para su uso. La consecuencia inmediata de ello es que el drama pierde su identidad y todas las posibilidades que nos ofrece para la educación, según hemos señalado en el apartado anterior. Por supuesto, tampoco se le ofrece un espacio en el currículum, sino que se emplea según convenga su uso.

\subsection{Modelo "asignatura separada"}

El drama pasa a formar parte exclusiva de la Educación Artística y se ubica dentro de la misma como una asignatura separada del resto que, como tal, cuenta con un currículum propio. Detrás de esta concepción encontramos además un entendimiento del currículum escolar en materias de conocimiento independientes, sin relación unas con otras, por lo que el aprendizaje globalizado, que caracteriza la apuesta que, por ejemplo la LOGSE hacía para la dramatización en la Educación Primaria, desaparece. Además, este modelo llevaría a entender el uso del drama restringido a una asignatura artística, perdiendo su relación con el resto del currículum.

${ }^{21}$ Psme: Personal, social and moral education. La educación personal, social y moral se contempla en el currículum inglés como una asignatura del currículum de Educación Primaria.

(C) Ediciones Universidad de Salamanca

Teor. educ. 19, 2007, pp. 225-252 


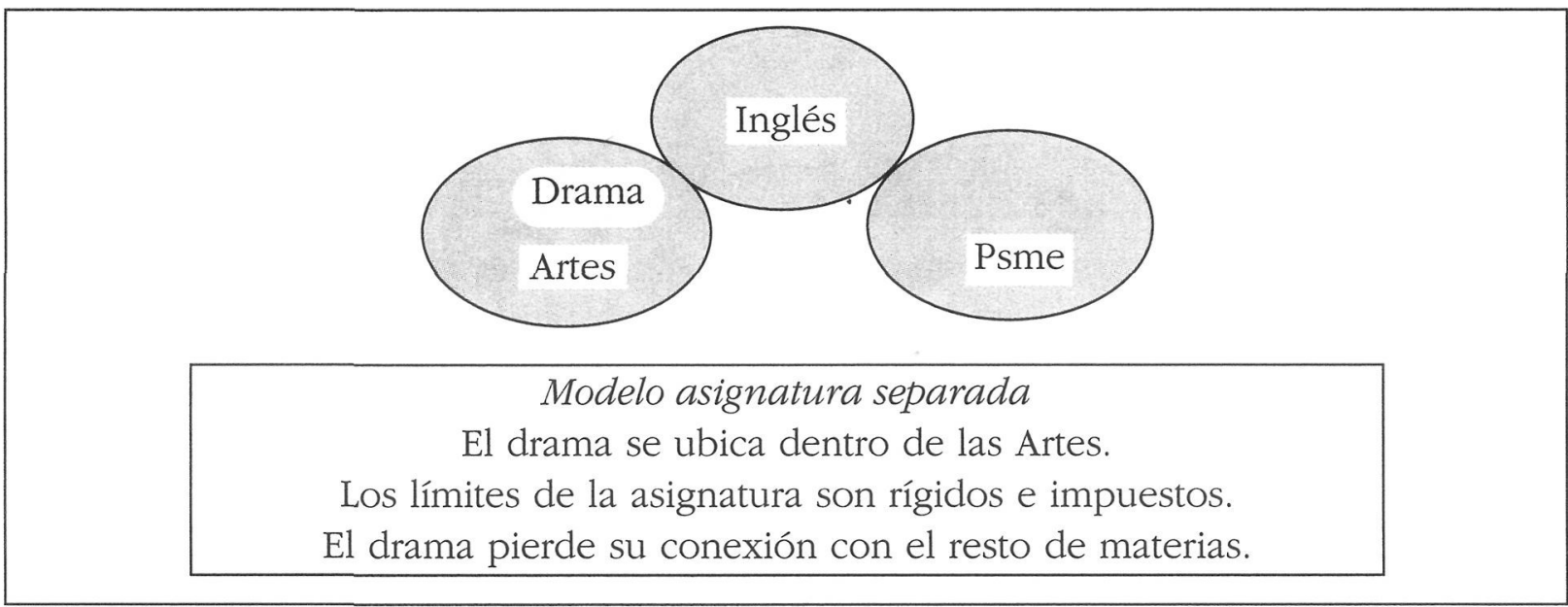

Es cierto que la Dramatización, como materia artística, tiene entidad suficiente para ser enseñada, al igual que la Música o la Plástica, las cuales gozan de una mayor tradición en nuestro currículum escolar de Educación Primaria. Por otro lado, esto ayudaría a una mejor formación cultura ${ }^{22}$ de nuestros alumnos, al igual que a generarle una sensibilidad y unas habilidades iniciales hacia la actividad teatral, tan desvalorizada en general por los jóvenes. En la actualidad, la defensa de la existencia de este espacio propio en el currículum no le quita fuerza en manera alguna al argumento que sostenemos de que el drama se halle en todo el currículum como medio de aprendizaje, tal como vemos en el siguiente modelo.

\subsection{Modelo Integrado}

Desde este modelo percibimos el drama como aquel medio que permite a los alumnos un aprendizaje significativo, al dotar de significado un concepto, un evento, una idea, etc. El alumno, mediante el drama vivencia un proceso que le lleva a tomar decisiones en un mundo imaginario, pero relacionado con el mundo real, con lo que construye nuevos significados del contenido con el que trabajamos.

Esta percepción del drama reconoce la existencia de unas características propias del mismo porque sabemos que son éstas las que hacen posible generar ese significado nuevo y las que despiertan una empatía por parte del estudiante hacia el contenido con el que trabajamos. Es decir, el drama es, simultáneamente, un

22 John SOMERs $(1994,7)$ escribe su libro Drama in the curriculum desde la siguiente premisa: $: E l$ drama y las artes en general tienen una función indispensable en nuestra cultura [anglosajona] y esto debe ser reflejado en el currículum de nuestro sistema educativo". Esta certeza para defender el espacio del drama en la educación atendiendo a la formación cultural de los alumnos está unida también a la del reconocimiento del espacio del drama como medio de aprendizaje en el resto de las áreas del currículum. 
medio de aprendizaje para todo el currículum con un cuerpo propio de conocimientos y procedimientos ${ }^{23}$.

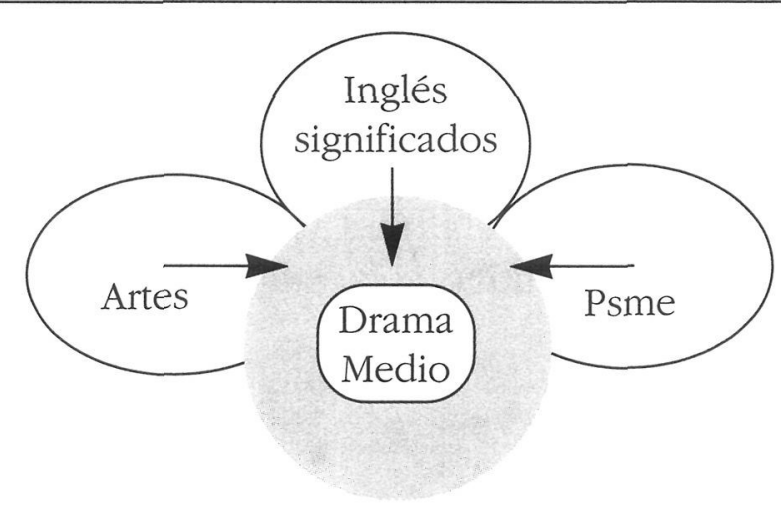

Modelo Integrado

El drama facilita nuevos significados a las asignaturas mediante la representación y es estudiado como un medio de representación con un cuerpo propio de habilidades, conceptos y conocimientos.

En esta dirección, son numerosas las publicaciones en el ámbito anglosajón y larga la experiencia que tienen en las escuelas de este tipo de uso del drama en la educación en relación con las diversas áreas del conocimiento. Una de sus pioneras en esta apuesta del drama como medio para el aprendizaje en todo el currículum

23 Para ilustrar esta idea con un ejemplo del uso del drama desde esta perspectiva, nos parece importante expresar las diferentes experiencias de aprendizaje que pudimos observar, en diversas áreas, a raíz de una sesión de drama en un colegio público de Educación Infantil y Primaria en Inglaterra. Los niños trabajan con el drama en una sesión que gira en torno a "la montaña". Desde la historia de una niña que va un día a la montaña, empiezan a trabajar con sus cuerpos diferentes oficios que pueden existir en torno a la montaña (sembrador, segador, el que recoge fruta, el que la utiliza para pasteles, etc.), así como sus correspondientes acciones. Por otro lado, construyen, en pequeños grupos, cuadros corporales en los que se encuentren representados los diferentes componentes que puede haber en una montaña (hierba, piedras pequeñas, rocas, riachuelos, flores, etc.). También trabajan con los posibles daños que el hombre causa a las montañas (basura, fuego, tala de árboles sin medida, arrancar flores...). En esta sesión se trabaja desde lo lúdico con los conceptos previos de la clase, se experimenta con el cuerpo, se generan nuevas ideas y sentimientos hacia el mundo de la montaña y se reflexiona sobre ellos. Una vez que finaliza la sesión, en el área de Conocimientos del Medio, durante una semana trabajan las montañas, aplicando y retomando parte de la sesión. En Arte crean un collage precioso sobre una montaña, con todos sus componentes y en Lengua, aprovechan la sesión para trabajar la escritura creativa construyendo una historia a partir de alguna de las vivencias en la clase de drama, los tiempos verbales y los pronombres y utilizando siempre como ejemplo la sesión. Sin duda, la participación de los alumnos aumenta y es cualitativamente diferente, al remitirles a un momento que ellos suelen valorar como divertido y lleno de contenido. 
escolar fue Dorothy Heathcote, quien elaboró una teoría del proceder del drama en la educación, llamada "Mantel de Expertos" (Heathcote y Bolton, 1995). De sus métodos y pensamiento existen numerosas referencias en toda la corriente anglosajona, como lo refleja Wagner (1979) $)^{24}$. Otra de las aportaciones nada desdeñables a la consolidación del drama como medio de aprendizaje procede de autores como Bolton (1984) 25 .

Nosotros defendemos, en coherencia con lo expuesto hasta el momento, la validez de este modelo para la escuela frente a los demás, considerando al drama como un aprendizaje más significativo y creativo, desde el cultivo del trabajo en grupo.

\subsection{Modelo Cultural}

A él nos referimos para indicar las enormes ventajas que el drama ofrece a la educación, en la medida que éste trae a la escuela la experiencia de la comunidad y la acerca a la realidad de la calle. El drama requiere de la generación de un contexto para su desarrollo y éste suele tener como protagonista a las relaciones humanas en diversos ámbitos o momentos, acercándole a los problemas de diversas comunidades. En este sentido, el drama forma parte de la educación para la diversidad e interculturalidad en la escuela ${ }^{26}$.

Por otro lado, el drama no se circunscribe tan sólo a la escuela, sino que va más allá, siendo igualmente válido para trabajarlo en ámbitos externos a ésta, por ejemplo en el área de la animación sociocultural o en actividades extraescolares de otro tipo.

${ }^{24}$ Se trata de la obra más representativa en este sentido de Wagner, es la que lleva por título Dorothy Heathcote: Drama as a Learning Medium.

${ }^{25}$ En España, y entre las experiencias pioneras desde la Universidad, valga como ejemplo concreto el proyecto que se llevó a cabo para la enseñanza de la Historia mediante la dramatización en un Instituto de Educación Secundaria sevillano (NúNezz CuBERo, 1976). Entre los resultados de dicha experiencia, se destacaban: mejores resultados en las pruebas de rendimiento de la materia, mayor participación, motivación ante la asignatura, soltura y fluidez verbal y espíritu crítico de los alumnos.

${ }^{26}$ Esto lo podemos encontrar en la obra de Grady (2000) Drama and Diversity. En ella se exponen diversas experiencias de trabajo, desde el drama, sobre temas como son la pobreza, el género o la diversidad cultural. 


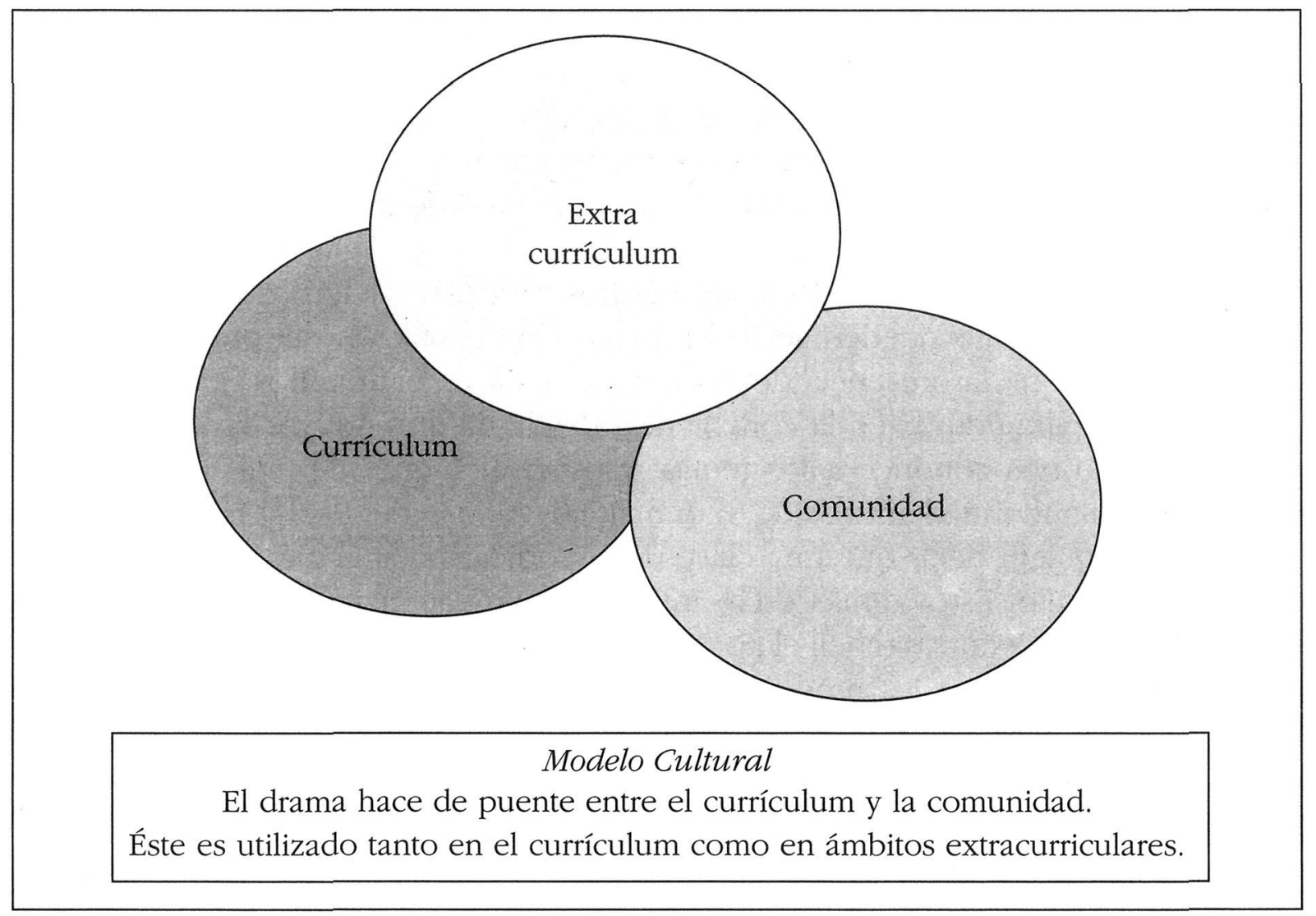

\section{LA DRAMATIZACIÓN EN LA EDUCACIÓN EN VALORES}

Hemos querido dejar para el final uno de los aspectos que, en nuestra opinión, más necesita la escuela actual, y en el que la dramatización presenta todo su potencial, como lo muestran multitud de experiencias en diferentes países y contextos socioeducativos. En efecto, en una sociedad en la que la propuesta social a los jóvenes se basa en gran medida en el éxito, el hedonismo como ideal de vida y la competitividad individualista, la escuela aparece como uno de los espacios, cada vez más reducidos, en los que la batalla por una educación cívica, moral y en valores ha de defenderse como aspecto primordial (Martínez Martín et al., 2003). Coincidiendo con autores como Needlands (1992), Winston (2000), Grady (2000), Motos (2003) o Somers (1994), el hecho de que el drama trate de las relaciones humanas, haciendo uso de todos los lenguajes para su exploración y manifestación, nos parece la razón fundamental por la que éste debe estar presente en el currículum escolar. Esto quiere decir que el drama, además de enriquecer la expresión y la comunicación, desarrolla la comprensión sobre las relaciones con los otros, desarrollando y enriqueciendo las capacidades sociales de cada uno, tan necesarias en la formación integral de toda persona. Cuando se unen las posibilidades pedagógicas que la dramatización ofrece con los objetivos de la educación social, se produce una dinámica muy importante que permite a los profesores 
favorecer una enseñanza activa y participativa. No nos cabe duda de que el contexto originado desde la dramatización en un aula, tanto con niños como con jóvenes o adultos, construye uno de esos espacios efectivos para la socialización de los participantes, incluyendo la del profesor. De esta manera, el drama se nos presenta en la escuela como una herramienta educativa para el desarrollo personal y social. A través de él podemos abordar la enseñanza de habilidades sociales (Ruiz et al., 2003), destinada a su vez a potenciar algunos aspectos básicos de las relaciones interpersonales, como pueden ser la escucha y la aceptación del otro ${ }^{27}$. Consideramos por ello que la presencia de la dramatización en el aula nos ofrece grandes posibilidades para educar en la convivencia desde un aprendizaje vivencial.

Todo ello nos conduce a los temas transversales que, de una u otra forma, estamos trabajando mediante el juego dramático (Alonso del Real y Ferreras, 1995), sin que esto quiera decir que una clase deba dedicarse específicamente a uno de ellos en particular. Estos temas están íntimamente relacionados con la educación en valores. Consideramos difícil el aprendizaje de los mismos desde el ámbito puramente intelectual, pues los niños, más que escuchar hablar de valores, necesitan, como expresa Mantovani (2002, 8-9) "verlos, sentirlos, vivirlos con la cabeza, el corazón y el cuerpom. El juego dramático permite llegar a esta vivencia. Algunos de estos temas transversales son:

a. Educación para la convivencia. La orientación de todas y cada una de las sesiones debe tener un carácter colectivo, y en ellas se trata de conjugar la creación personal y la colaboración, evitando la competitividad excluyente.

b. Educación no sexista. La familiaridad que el alumno tiene que adquirir necesariamente en el trato con personas de otro sexo puede ser el más recto camino para evitar conductas discriminatorias y, simultáneamente, para lograr más fluidez y naturalidad en las relaciones personales.

c. Educación para la solidaridad. En la medida que el juego dramático exige la escucha al entorno, se irá pidiendo al alumno que aprenda a descubrir los problemas sociales que en él existen, de manera que se vaya generando en él una sensibilidad social.

d. Educación para la paz. La dramatización como campo de acción es una herramienta de gran eficacia para que los alumnos interioricen actitudes

\footnotetext{
27 En nuestro trabajo con los niños y niñas hemos buscado la expresión propia, espontánea y creativa, de cada sujeto individual (en este caso en la etapa infantil, pero igualmente aplicable a edades juveniles y adultas). También hemos trabajado generando pequeños conflictos que se tendrán que ir resolviendo desde propuestas personales, que pueden ser aceptadas y/o transformadas por el grupo de trabajo. Con ello hemos pretendido educar las habilidades sociales desde un aprendizaje situacional, partiendo siempre de la propia experiencia vivida. Por ejemplo, como habilidades generales, propusimos dos que creemos muy importantes e íntimamente relacionadas: el aprendizaje cooperativo, que va más allá del simple trabajo en grupo, y el respeto y la aceptación de los demás, ambas tratadas como elementos básicos para la integración social.
} 
como el diálogo, la tolerancia, la reconciliación, la comprensión y la cooperación, valores estos necesarios para promover una cultura de paz ${ }^{28}$.

e. Educación para el cultivo de la dimensión filosófica y religiosa. Mediante la dramatización podemos profundizar en experiencias humanas como el dolor, la enfermedad, la muerte, el sentido del vivir y la comprensión de la historia personal y colectiva.

Consideramos que frente al egoísmo, la competitividad, la superficialidad-frivolidad y el individualismo que imperan en nuestra sociedad, y a favor de una educación que transmita valores de justicia, igualdad, fraternidad y dignidad humana, urge la necesidad de que nuestras escuelas eduquen para la paz, el perdón, la convivencia y el diálogo. En este sentido, es imperiosa una educación en actitudes y habilidades de colaboración que promueva comportamientos de construcción social, de democracia real, que favorecen además el desarrollo integral: cognitivo, volitivo, afectivo, psicosocial del alumnado... La dramatización es un instrumento idóneo para desarrollar esas habilidades interpersonales, que a su vez contribuyen a mejorar las habilidades intelectuales y académicas.

No quisiéramos terminar sin comentar que hemos encontrado antecedentes de este tipo de propuesta en algunos programas europeos como, por ejemplo, el Proyecto MUS-E, Música en Europa. Se trata de un proyecto basado en el aprendizaje desde las artes, que pone el arte al servicio de la potenciación de la autoestima en colectivos infantiles y juveniles, y que, en algunos casos, está siendo desarrollado en zonas marginales, multiculturales, con gran absentismo escolar y con altos índices de violencia. Mediante la dramatización se están obteniendo excelentes resultados en estos complejos contextos, que van incluso más allá de las previsiones iniciales ${ }^{29}$.

28 En esta misma línea, recomendamos el artículo de Moreno Ramos (2000).

29 El proyecto MUS-E comenzó a elaborarse en agosto de 1992, siendo una propuesta de la Fundación Internacional Yehudi Menuhin (IYMF), que debe su nombre al famoso violinista fallecido en el 2000. Éste apoyó y estimuló todas las actividades de la Fundación, especialmente a través de su testimonio y convencimiento de que la violencia y la marginación en las escuelas y la desmotivación de los estudiantes podían ser combatidas por medio de la educación artística. El proyecto está dirigido a centros educativos de Educación Primaria con una fuerte deprivación social y una elevada realidad multicultural en sus aulas. El programa MUS-E integra a diferentes artistas en las aulas de centros escolares trabajando directamente con las clases, junto con el apoyo de los maestros tutores. Las actividades artísticas MUS-E ocupan al menos el 10\% del tiempo escolar. El fin principal de éstas, tomando las palabras de Poncelet $(2002,4)$, secretaria general de la IYMF, es "prevenir la violencia y el racismo, la exclusión social y la falta de respeto, la solidaridad y tolerancia, a través de la enseñanza de las artes".

Son al menos doce los países europeos que participan en este programa, llegando a más de 10.000 escolares. La implantación del programa se lleva a cabo mediante iniciativas privadas en algunos países y públicas en otros. En el caso de España, país en el que el proyecto presenta una consolidación estimable (BARón, 2000), se cuenta con el apoyo del Ministerio de Educación y Cultura y el Ministerio de Trabajo y Asuntos Sociales. En uno de los encuentros nacionales celebrado en Ávila en febrero del 2003, al que asistimos, se valoraba como resultados muy positivos, el crecimiento de la autoestima personal de los niños implicados en el programa y la motivación en la tarea tanto de aprendizaje, como 


\section{BiBLIOGRAFÍA}

Alonso del Real, G. y Ferreras Estrada, J. (1995) Aula de Teatro. Sevilla, Rayuela.

BARÓN, E. (2000) El programa MUS-E: integración social y tolerancia a la diversidad a través de actividades artísticas, en $V$ Seminario Internacional MUS-E: Las artes en el umbral del siglo XXI. Madrid, Fundación Yeduhi Menuhin, 27-29.

BeEtlestone, F. (2000) Niños creativos, enseñanza imaginativa. Madrid, La Muralla.

BerCeBAL, F. (1995) Drama. Un estadio intermedio entre juego y teatro. Ciudad Real, Naque.

BolTon, G. (1984) Drama as Education: An Argument for Placing Drama at the Centre of the Curriculum. London, Longman.

BorTHwick, G. (1982) Hacia una educación creativa. Madrid, Fudamentos.

Bruner, J. (1984) Juego, pensamiento y lenguaje, en LinAZA, J. (ed.). Jerome Bruner: Acción, pensamiento y lenguaje. Madrid, Alianza Psicología.

Cervera, J. (1991) La creatividad dramática, en Marín Ibáñez, R. y De la Torre, S. (coords.). Manual de la Creatividad. Barcelona, Vicens Vives, 419-423.

- (1996) La dramatización en la escuela. Madrid, Bruño.

Clausse, A. (1951) Introduction à l'bistorie de l'éducation. Bruxelles, Maison d'Édition A.

Díez, M.; Mateos, E. y Menchen, F. (1980) La creatividad en la EGB. Madrid, Marova.

Dillon, G. A. (2001) Educación Artística y Creatividad, Homo Artisticus, 4, 12-14.

EInes, J. y Mantovani, A. (1980) Teoría del juego dramático. Madrid, MEC, INCE.

FAURE, E. et al. (1972) Aprender a Ser. Madrid, Alianza Universitaria-Unesco.

Ferrer, M.; Motos, T. y Navarro, A. (2003) Dramatització i Teatre, Articles de Didáctica de la Llengua i de la Literatura, 29, 7-9.

Fleming, M. (1994) Starting Drama Teaching. London, David Fulton.

GaRCía CaRrasco, J. (1982) Creatividad y teoría del currículum, Innovación Creadora, 149-161.

- (2004) La experiencia artística, Addenda a la II Ponencia: Los lenguajes de las Artes. Escenas y Escenarios en Educación, XXII-Site-Sitges Conference.

GARDNER, H. (1999) Inteligencias múltiples. La teoría en la práctica. Barcelona, Paidós.

Goleman, D. (1996) Inteligencia emocional. Barcelona, Kairós.

GRADY, S. (2000) Drama and Diversity. A pluralistic perspective for educational drama. Portsmourth, Heinemann.

HAAS, R. B. (1948) The school Sociatrist, Sociatry, 2, 283-321.

HANSEn, B. (1948) Sociodrama. A Methodology for Democratic Action, Sociatry, 2, 347-363.

Heathcote, D. y Bolton, G. (1995) Drama for Learning: Dorothy's Heathcote Mantle of Expert Approach to Education. Porstmouth, NH, Heinemann.

KueIN, A. F. (1956) Role Playing. Nueva York, Association Press.

LAFERRIÈRE, G. (1993) La improvisación pedagógica y teatral. Bilbao, EGA.

- (1997) La pedagogía puesta en escena. El artista pedagogo y el modelo de formación basado en la mezcla y el mestizaje. Ciudad Real, Ñaque.

\footnotetext{
de enseñanza, ya que gracias a la educación artística se abrían en los centros nuevos espacios de comunicación más personal e individualizados. Esto hacía posible, por un lado, que los niños descubriesen sus posibilidades en todos los ámbitos (cognitivos, expresivos, afectivos) y, por otro lado, que los maestros desarrollasen las capacidades de sus alumnos y nuevos recursos para la enseñanza.

Para aquellos que estén interesados en ampliar la información sobre este proyecto pueden consultar las siguientes páginas web: http://europa.eu.int/comm/education/connect y http://www.fundacionmenuhin.org.
} 
Mantovani, A.; Ruano, G.; Lazcano, M. J. y Ramiro, I. (1993) Dramatización. $2^{o}$ ciclo de Educación Primaria (guía para el profesor). Madrid, Edelvives.

- (2002) ¿Es posible construir una pedagogía futurista?, Homo Artisticus, 4, 8-9.

Marín Ibáñez, R. (1991) Indicadores de la creatividad, en Marín IBáñez, R. y De la ToRre, S. (coords.). Manual de la Creatividad. Barcelona. Vicens Vives, 100-109.

Martínez Martín, M.; Puig Rovira, J. M. y Trilla Bernet, J. (2003) Escuela, profesorado y educación moral, Teoria de la Educación, 15, 57-94.

Maslow, A. (1987) La personalidad creadora (3. ${ }^{a}$ edición). Barcelona, Kairós.

Moreno, J. L. (1946) Psychodrama, vol. I. Nueva York, Beacon House.

Moreno Ramos, J. (1999) Didáctica del vocabulario en la E.S.O.: Estudio empírico. Tesis Doctoral. Universidad de Murcia.

- (2000) El teatro como camino para la paz, Ñaque: Teatro, Expresión y Educación, 17, 28-29.

Moтоs, T. (1992) Las técnicas dramáticas: Procedimiento didáctico para la enseñanza de la lengua y la literatura en la educación secundaria. Tesis Doctoral. Universidad de Valencia.

- (1995) Teatro: Dinamización y educación plural, en LAFERRière, G.; TORDERA, A. y Motos, T. Los escenarios de fin de siglo: Teatro, tecnologia y educación plural. Valencia, Universidad Internacional Menéndez Pelayo, 141-164.

- (1996) Dramatización y Técnicas dramáticas en la enseñanza y el aprendizaje, en GaRCía Hoz, V. Enseñanzas artísticas y Técnicas. Madrid, Rialp, S.A., 113-164.

- (2003) Bases para el taller creativo expresivo, en Gervilla, A. (ed.) y otros. Creatividad Aplicada. Una apuesta de futuro. Madrid, Dykinson.

Motos, T. y Navarro, A. (2003) El papel de la dramatització en el currículum, Articles, 29, 10-28.

Motos, T. y Tejedo, F. (1996) Prácticas de Dramatización. Madrid, Ed. J. García Verdugo; reeditado en Madrid por la editorial Avispa (1999).

MOYLES, J. R. (1990) El juego en la educación infantil y primaria. Madrid, Morata.

NAVARRO, M. R. (2003) La formación inicial del profesorado en las Universidades públicas españolas para el uso de la dramatización en el aula, Enseñanza, 21, 181-198.

- (2004) Buscando el espacio del drama en el currículum de educación primaria, Naque, 35, 8-13.

- (2005) El valor pedagógico de la dramatización: su importancia en la formación inicial del Profesorado. Tesis Doctoral. Universidad de Sevilla.

NEELANDS, J. (1984) Making Sense of Drama. London, Heinemann.

- (1992) Learning through Imagined Experience. London, Hodder and Stoughton.

NúÑEz CuBERo, L. (1976) Dramatización de la Historia. Una experiencia de animación escolar. Análisis de resultados, en Memoria de Actividades, Informe III, ICE. Sevilla, Universidad de Sevilla, 148-152.

- (1979) El rol del profesor ante la dramatización, Boletín C.N.I.N.A.T.Ministerio de Cultura, 5, 1-4.

- (1998) Hacia una escuela creativa, Cuestiones pedagógicas, 14, 69-74.

NúÑEz CuBERo, L. y ROMERo, C. (2004) La educación emocional a través del lenguaje dramático, Addenda a la II Ponencia: Los lenguajes de las Artes. Escenas y Escenarios en Educación, XXII-Site-Sitges Conference.

O'NeILl, C. (1995) Drama Words: A Framework for Process Drama. Portsmouth, NH, Heinemann.

Poncelet, M. (2002) La Fundación Internacional Yehudi Menuhin, Homo Artisticus, 4, 4-6. 
Ruiz Curado, S.; Navarro, M. R. y Fernández Calderón, D. (2003) Habilidades Sociales en Educación, en Gull Bozal, A. (coord.). Psicología Social del Sistema Educativo. Lineas actuales de trabajo e investigación. Sevilla, Kronos, 263-318.

Slade, P. (1954) Child Drama. London, London University Press. Traducido en 1978: Expresión Dramática Infantil. Madrid, Aula XXI, Santillana.

SOMERS, J. (1994) Drama in the curriculum. London, Cassell.

Tejerina, I. (1994) Dramatización y teatro infantil. Dimensiones psicopedagógicas y expresivas. Madrid, Siglo XXI.

- (1997) Juego dramático y educación creadora, en Jornadas Internacionales Teatro y Niño. Teatro para ver, Teatro para actuar. Tolosa, Festival Internacional de Marionetas, Tolosako Ekinbide Etxea y Centro de Iniciativas de Tolosa, 71-81.

TORrance, E. P. y Myers, R. E. (1976) La enseñanza creativa. Madrid, Santillana.

UCAR, X. (1992) El teatro en la animación sociocultural. Técnicas de Intervención. Madrid, Diagrama.

VEGA, R. (1981) El teatro en la educación. Buenos Aires, Plus Ultra.

VyGOTSKI, L. S. (1996) La imaginación y el arte en la infancia (3. ${ }^{a}$ edición). Madrid, Akal.

WAGNER, B. J. (1979) Dorothy Heathcote: Drama as a Learning Medium. London, Hutchinson.

- (1998) Educational Drama and Language Arts. What research shows. Portsmouth, Heinemann.

Wallach, M. A. y Kogan, N. (1983) Creatividad e inteligencia en el niño, en SToM, R. D. Creatividad y educación. Barcelona, Paidós.

WinNicotT, D. W. (1982) Realidad y juego. Barcelona, Gedisa.

Winston, J. (2000) Drama, Literacy and Moral Education. London, David Fulton, 5-11. 